\title{
Guidelines and Acceptable Postharvest Practices for Organically Grown Produce
}

\author{
Anne Plotto ${ }^{1}$ and Jan A. Narciso \\ U.S. Department of Agriculture, Agricultural Research Service, Citrus and Subtropical Products Laboratory, 600 \\ Avenue South, NW, Winter Haven, FL 33881
}

\begin{abstract}
Additional index words. National Organic Program, Organic Food Production Act of 1990, handling, processing
Abstract. Organic foods are produced using agricultural practices that emphasize renewable resources and conservation of soil and water. Horticultural crops are grown and processed without synthetic fertilizers, pesticides, ingredients and processing aids. Crops or ingredients derived from genetic engineering, and use of ionizing radiation are prohibited in organic production. The challenge is to deliver produce that has the same safety, quality and shelf life as conventional products, with a limited array of tools available for sanitation and postharvest treatments. Organic operators, professionals servicing the industry, as well as researchers involved in organic production practices, should be aware of all the points in the process of storing, handling and transforming horticultural crops where accidental contamination could occur, and thus compromise organic integrity. This presentation summarizes the major points of the National Organic Program for processing and handling, and gives suggestions for postharvest research. For example, finding organic alternatives for postharvest decay control is critical to maintain food safety. Additionally, ingredients compatible for fresh cut and produce coatings must be developed for the organic market for food safety and competitiveness.
\end{abstract}

Demand for organic foods has had a very rapid growth in the last 10 years. Although most recent data show a plateau in sales in the European market, sales continue to increase on other continents, in countries such as China, Brazil and South Africa, and the United States, which results in a continuing growth in the global world market (Sahota, 2004). Land areas in organic production have increased too: over 26 million hectares (62.4 million acres) are under organic production worldwide (Yussefi, 2005). In the United States, the organic market grew from $\$ 3.57$ billion in 1997 to $\$ 10.38$ billion in 2003 , and is predicted to reach $\$ 14.5$ billion in 2005 (Organic Trade Association 2004). As production grows, the market is becoming more sophisticated, and horticultural products need to be stored longer, transported over longer distances, and/or processed more intensively. The need for disease-free fruit or vegetables is as important as for nonorganic produce; however, the tools to combat postharvest diseases while maintaining organic integrity are more limited. For processed foods, ingredients that can be used conventionally may not be allowed for an organic product. The processing system and/or facility may have features that are not acceptable in an organic production system. Thus, it is important for the grower, packer, manufacturer, handler, or for any professional providing services to the organic industry, to be aware of all the intricacies of the National Organic Program (NOP) regulations as written in the Code of Federal Regulations, Title 7, Part 205 (7 CFR 205), and understand the principles of the Organic Foods Production

\footnotetext{
Mention of a trademark or proprietary product is for identification only and does not imply a guarantee or warranty of the product by the U.S. Department of Agriculture. The U.S. Department of Agriculture prohibits discrimination in all its programs and activities on the basis of race, color, national origin, gender, religion, age, disability, political beliefs, sexual orientation, and marital or family status.

${ }^{1}$ To whom reprint requests should be addressed; e-mail plotto@citrus.usda.gov.
}

Act of 1990 (OFPA) before engaging in organic production and certification. Likewise, researchers should know the requirements for organic production and handling in order to maximize research efforts that benefit organic farmers and processors.

\section{WHAT IS ORGANIC FOOD?}

Organic farming emphasizes the use of renewable resources, land management that maintains natural soil fertility, water conservation, rich biodiversity, and long-term sustainability (7 CFR 205.2). It is a "systems approach" that relies on crop rotations, soil building, and biological pest control(UNCTAD, 2003). Food must be produced without synthetic chemicals, except for those specifically allowed by regulations, and without substances (nonsynthetic and nonagricultural) prohibited by regulations, including no sewage sludge, ionizing radiation or bioengineering (7 CFR 205.105).

Consumers can recognize foods that are produced organically when they are certified by a government-accredited agency, and display a valid form of certification. In the United States, organic foods can be recognized by the USDA organic logo (Fig. 1), which gives the consumer assurance that the product indeed was produced and processed according to organic standards. That symbol, often accompanied with a certification statement, means that the production farm and all facilities downstream have been inspected, inputs and ingredients were verified to be in compliance with the rules, and an appropriate audit trail was maintained. Consumers of organic foods expect that the products are microbiologically safe as with any other food, pesticide free, and antibiotic and growth hormone free for animal products. Some might believe organic products are healthier, however, no claim is explicitly made in terms of nutritional value, although organic produce was generally found to have much lower levels of pesticide residue (Benbrook, 2004).

\section{BASIC REQUIREMENTS}

For a certified organic grower washing or packing his or her own fruit, a cooperative of growers receiving, sorting and packaging fruits from certified organic and/or noncertified organic growers, or a food processor processing a portion or all of its production as certified organic, the following basic principle applies: the organic integrity of a food must be maintained from the farm to the consumer. There must be no contamination of the organic product and its packaging with prohibited substances; there must be clear separation from, and no co-mingling with nonorganic products. Ingredients used in the finished product should be organic or otherwise approved, and records should be sufficient to demonstrate compliance with the NOP standards. Records must be made available for inspection and allow a complete

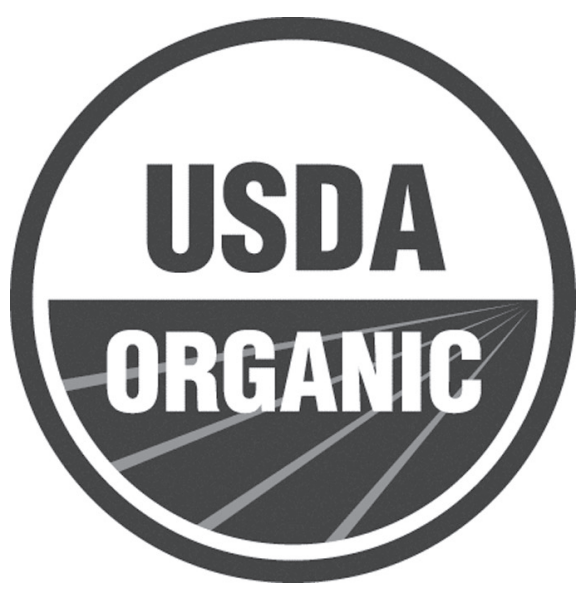

Fig. 1. The USDA organic seal may be used to label foods that contain $100 \%$ or $95 \%$ organic ingredients. The USDA letters are green on a white background, and the ORGANIC letters are white on a green background with lines that represent a plowed field, and the logo is outlined with a brown circle. 
audit trail (7 CFR 205.103). The NOP requires the operator to submit an organic system plan (OSP), which includes a detailed description of the process, monitoring procedures, and description of management practices to insure the organic integrity of the product (7 CFR 205.201). The list of each substance used during production or handling must be provided, as well as a description of the record keeping system (7 CFR 205.201). In many ways, the OSP is similar to the implementation and documentation of hazardous critical control points (HACCP) for food safety, only in this case, the critical control points (or organic control points) are points in the process where contamination of the organic product with nonorganic materials could occur. The discussion below will provide a general guideline of points to consider in an OSP when packing or processing organically produced horticultural crops. The reader should always refer to the original rule for detailed information (Title 7 CFR Part 205; references thereafter will here be noted for specific sections (§) of Part 205).

\section{INGREDIENTS AND PROCESSING AIDS}

The USDA identifies four labeling categories of organic products, depending on the product composition and percentage of organic ingredients. Products represented as " $100 \%$ organic" must contain only certified organic ingredients and use certified organic processing aids. Products sold as "organic[ must contain no $<95 \%$ organic ingredients; the remaining $5 \%$ or less of nonorganic ingredients must be consistent with the National List of nonagricultural (\$205.605) or nonorganically produced agricultural products (\$205.606). Calculating the percentage of organically produced ingredients is described in details under $\S 205.302$. Water or salt in processed products are not counted in the calculation of the percentage, by weight or by volume. For example, a fruit juice made with $100 \%$ organic fruit concentrate to which water is added can bear the label " $100 \%$ organic." Both " $100 \%$ organic" and "organic" products must follow labeling as described in $\$ 205.303$. Other product categories are "made with organic" (specified ingredients), which must contain no less than $70 \%$ organic ingredients, and products with $<70 \%$ organic ingredients, which may only identify the organic ingredients on the ingredient panel with an asterisk or with the word "organic," but may not display the USDA seal on the product package ( $\$ 205.305)$. Table 1 summarizes the prohibited production and handling practices for each of the categories.

Nonorganic ingredients in organic products ( $95 \%$ organic) may only be from the National List, and produced using processing aids from the National List ( $\$ 205.605$ and $\S 205.606)$. Among the nonagricultural substances (synthetic and nonsynthetic) allowed in or on organic fruit or fruit products are waxes (carnauba and wood rosin only). Ethylene can be used for postharvest ripening of tropical fruit and citrus degreening only. For fresh-cut fruit, citric acid and ascorbic acid may be used as $\mathrm{pH}$ adjusters and/or antibrowning agents; calcium chloride or calcium citrate as firming agents, and carrageenan, xanthan gum, and water-extracted gums (Arabic, guar, locust bean, carob bean) as coating materials. The above enumeration is not exhaustive, and the reader should refer to the National List for all substances allowed in organic food processing (§205.605; §205.606).

A thorough understanding of materials and ingredients used in organic processing is necessary to interpret the National List. For example, even though substances such as carnauba wax or wood rosin are allowed, they actually cannot be applied to a fruit as such unless they are formulated into microemulsions. Microemulsions used for waxes applied to fruits are made with a fatty acid such as oleic, linoleic, palmitic, myristic, and lauric acid, and a basic counterion such as the hydroxides of ammonium, sodium or potassium, morpholine, or, in the past, triethanolamine (Baldwin, 1994). But, morpholine and triethanolamine, while added to steam to prevent pipe corrosion, are strictly prohibited for use in an organic process if the steam is in direct contact with the organic food. Antifoams such as polydimethylsiloxane or silicon dioxide may be added, but they are not absolutely necessary to make a wax emulsion. For instance, a carnauba wax coating is most likely to also contain a fatty acid $(10 \%$ to $20 \%$ of solids), ammonia or morpholine (3\% to $10 \%$ of solids), and possibly an antifoam (Hagenmaier and Baker, 1997). The residual morpholine or ammonia in the coating makes such brands of carnauba wax prohibited for use on organic fruit; however, it should be possible to substitute morpholine with other acceptable bases. Manufacturers who desire to sell their products for use in organic foods or organic production systems should have their formulations and processes verified by the Organic Materials Review Institute (OMRI). The verification process is strictly confidential, suppliers can have their product(s) guaranteed acceptable for use in organic production, and users may use such products with confidence that organic integrity will not be compromised.

One word of caution for producers and manufacturer of organic products: if the intended market is for export, it is very important to verify which additives and auxiliaries are allowed by regulations that govern organic standards in the target market.

\section{FUTURE OF THE NATIONAL LIST}

The Organic Rule and the National List have evolved over the years from the organic movement grass-root to the drafting of the OFPA, the formation of the National $\mathrm{Or}$ ganic Standard Board (NOSB), and now the current legislation managed by the USDA. Each substance is thoroughly reviewed by a Technical Advisory Panel, then by the NOSB who makes recommendations to the NOP whether to include a new substance on that list (recommendations by the NOSB are not official policy until approved by the USDA). Criteria for approval of a synthetic substance include considerations regarding human health, environment, necessity for the production of the agricultural product, and compatibility with organic farming and handling practices (OFPA and 7 CFR 205.600). The National List currently comprises of a total of 165 synthetic and nonsynthetic allowed substances $(\$ 205.601$, $603,605,606)$, and nine prohibited nonsynthetic substances $(\$ 205.602$ and $\$ 205.604)$ (Federal Register, 2005a). In agreement with the Organic Food Production Act of 1990,

Table 1. Prohibited production and handling practices for the four organic products categories.

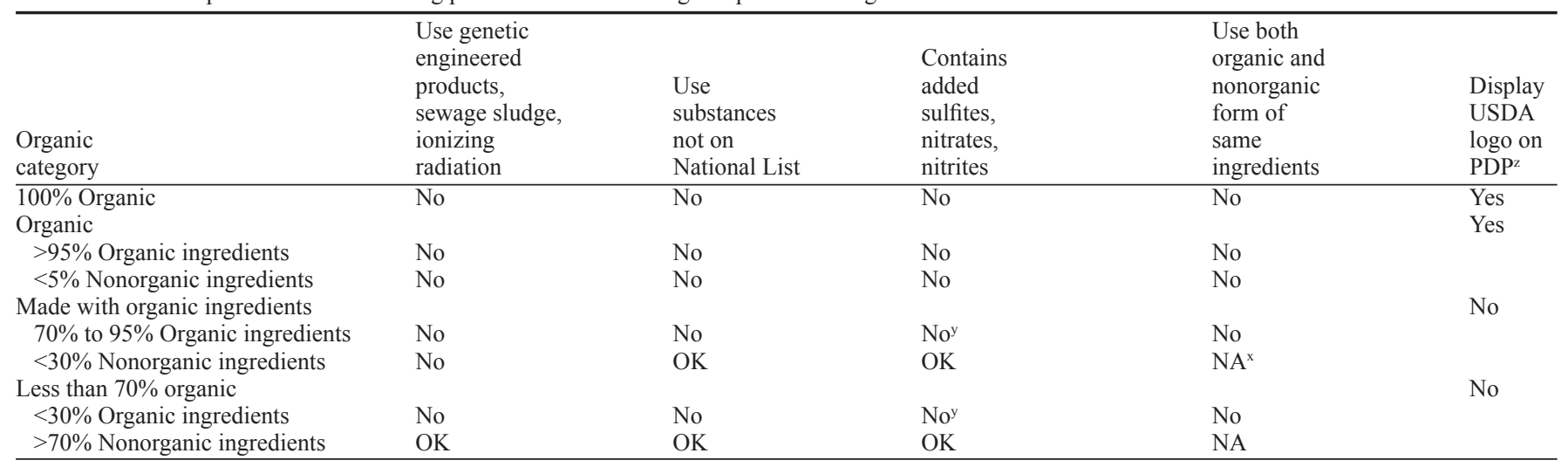

${ }^{2} \mathrm{PDP}=$ principal display panel.

'Except wine.

${ }^{\mathrm{x}} \mathrm{NA}=$ not applicable, provided the non organic ingredient is not labeled as organic and is not counted in the calculation of the product's organic percentage. 


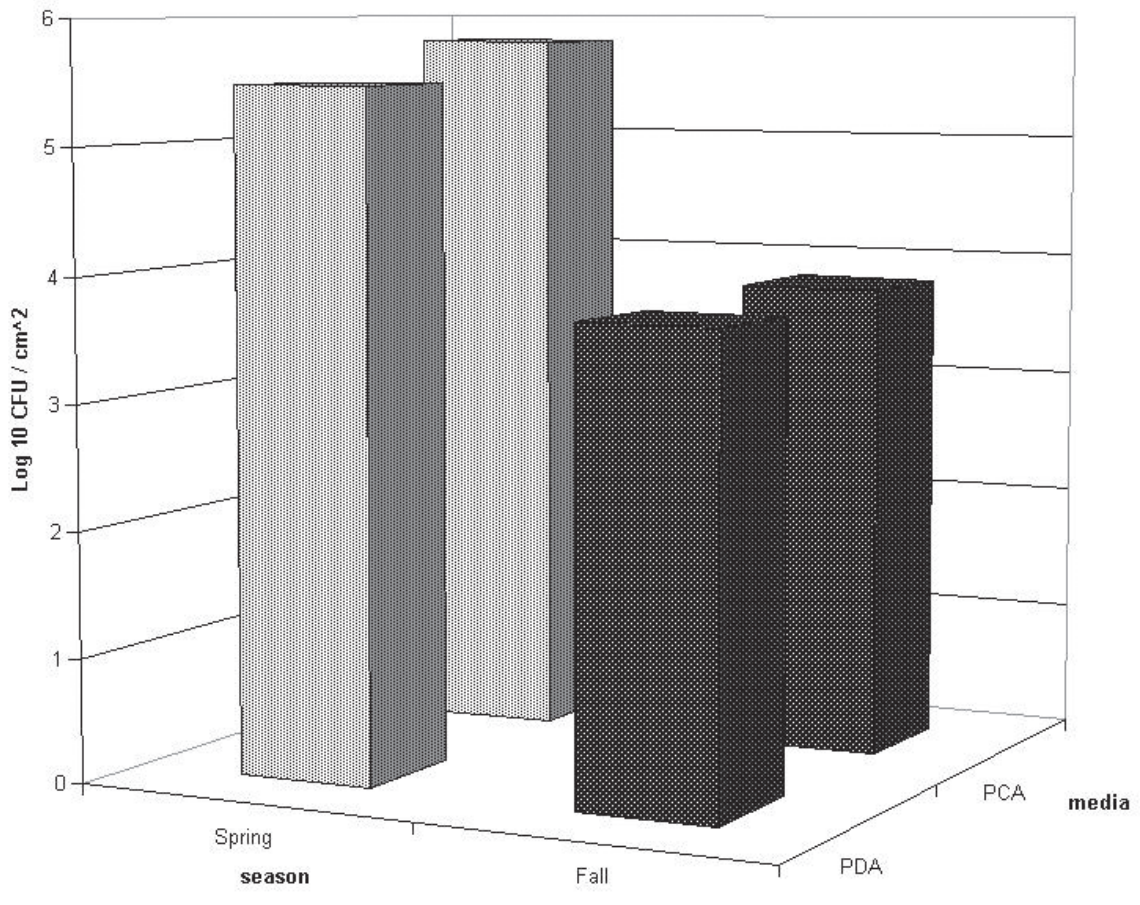

Fig. 2. Microbial population counts $\left(\mathrm{cfu} \cdot \mathrm{cm}^{-2}\right)$ isolated on potato dextrose agar (PDA) and plate count agar (PCA) from orange fruit surface sampled in the spring and fall.

the National List contains a sunset clause and unless reviewed and renewed, the current listings will expire on 21 Oct. 2007. The intent of allowing the use of synthetic or natural but nonorganic substances for a finite period was that ultimately, organic production practices should evolve to eliminate the need of such substances. Indeed, with the increasing market and production capacity, some ingredients such as starch, maltodextrin, and lecithin, can now be found from organic sources on the market. The Agricultural Marketing Service invited public comments (Federal Register, 2005a) that will be considered in re-evaluating the substances on the National List.

\section{CLEANING AND SANITATION}

When handling and packing fresh fruit or vegetables, great care must be taken to assure adequate sanitation. For organic fruit and vegetables, sanitation products must comply with specific regulations. In the case of the NOP, chlorine materials are allowed, as long as "residual chlorine levels in the water do not exceed the maximum residual disinfectant limit under the Safe Drinking Water Act" (42 USCA 300 f et seq., and $\$ 205.605$ (b)). The limit of free chlorine is currently established by the Environmental Protection Agency to be at 4 $\mu \mathrm{L} \cdot \mathrm{L}^{-1}$. The rule therefore does not address directly how much chlorine material can be put in the disinfecting or sanitizing water, but how much should be left in the water at the end of a wash. It is advised to monitor chlorine levels in water. Chlorine materials specifically allowed are calcium and sodium hypochlorite, and chlorine dioxide. Other allowed sanitation materials are ozone and hydrogen peroxide. These have the advantage that residual sanitizer

Facility pest management is based on prevention ( $\$ 205.271)$, and when a pesticide needs to be used, it must not contaminate the organic product or packaging material. Regular cleaning of the processing facility, removal of food sources and destruction of habitat constitute the first step in trying to maintain low pest pressure (Montecalvo, 2004). Whenever possible, control of the environment such as temperature, humidity, light, atmosphere and air circulation can be part of the pest management practices (\$205.271 (a)(3)).Additionally, thorough inspection of products and packaging entering the facility should be part of the prevention program. Rodents and crawling insects may be kept to a low level with regular building maintenance, and by keeping the waste dumpster some distance from the facility. Traps may be and should be used to monitor rodents and insects, and help keep their populations at low levels. Flying insects may be prevented from entering the facility with the use of air curtains and screen doors; light traps and insect electrocutors may be used as a physical means of control (Montecalvo, 2004). Lures and repellents consistent with the National List may be used (§205.271 (b), §205.601). Insect pheromones enter this category, and may be used to attract insects on sticky traps.

If preventative practices such as listed above are not sufficient to control pests, nonsynthetic or synthetic substances included on the National List may be applied $(\$ 205.271(\mathrm{c}))$. This includes boric acid as a structural pest control, and Vitamin $\mathrm{D}_{3}$ as rodenticide ( $\left.\$ 205.601\right)$. If any of the above procedures still fail to control an insect or rodent infestation, the USDA-NOP allows the use of synthetic pesticides, provided that all measures are taken to avoid contamination of the organic product (\$205.271(d)). The handler or manufacturer must notify the certification body of the pest problem and prove that all preventative measures have failed, for instance by providing a log of the pest activities, or a letter from an outside pest contractor. Thorough descriptions of how the organic ingredients, product and packaging will be protected from contamination must also be provided. Only then can anti-coagulant rodenticides such as bromadiolone be used in exterior bait stations (Montecalvo, 2004). Fumigation or fogging may also be performed, provided that all ingredients, packaging, and finished products are removed or isolated somehow from the treated facility. Food may be processed on equipment that has been treated with these prohibited chemicals only after a thorough cleaning. Movement of all inventory, and cleaning activities must be recorded, and this will be verified during a follow-up inspection. Overall, it is possible to conduct effective pest management while preserving organic integrity. Organic pest management, cleaning and sanitation operations should not compromise food safety at any level (Montecalvo, 2004). In addition, a handler may use substances to prevent or control pests as required by Federal, State, or local laws and regulations, provided that adequate measures are taken to prevent contact of the organic product or ingredient with the substance used (\$205.271(f))

\section{ISSUES AND RESEARCH NEEDS}

Postharvest research that could benefit organic growers and packers includes develop- 


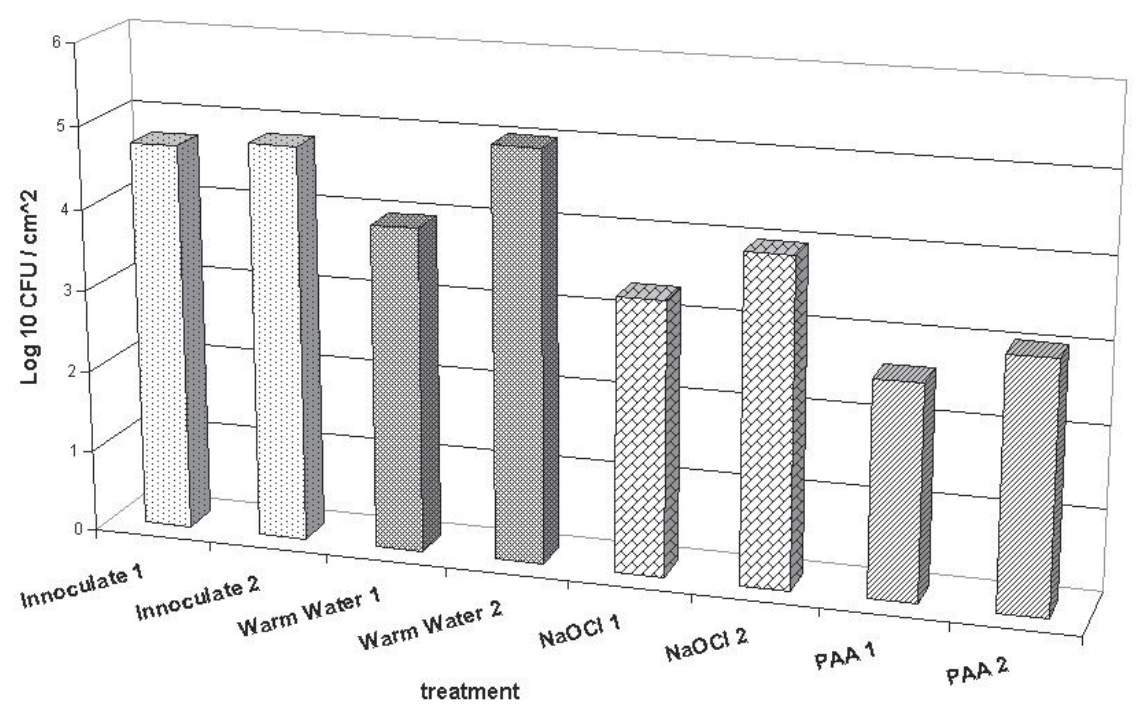

Fig. 3. Microbial counts $\left(\mathrm{cfu} \cdot \mathrm{cm}^{-2}\right)$ from orange fruit surfaces inoculated and subsequently treated with warm water, sodium hypochlorite $(\mathrm{NaOCl})$, or peroxyacetic acid (PAA) in a replicated experiment $(1$ and 2$)$.

ment of technologies for enhancing food quality in an organic compatible manner. Microbial control on horticultural crops after harvest is particularly critical for both consumer safety and product shelf life, but tools are not as widely available for organic as for conventional production systems. The limited use of fungicides in the field and post-harvest may lead to decay problems in storage. The researcher needs to consider a systems approach, with field evaluation of microflora before taking the appropriate sanitation steps. Postharvest strategies to control pathogens may include development of natural fungicides, including botanicals, or enhancing the plant response by stimulating production of elicitors in response to pathogen attack.

\section{EXAMPLE: ALTERNATIVES TO CHLORINE SANITIZER}

Chlorine is most commonly used for the sanitation of whole fruit and vegetable surfaces, and is allowed by the NOP rule ( $\$ 205.605(b))$. However, chlorine has limitations as its efficiency is dramatically reduced on exposure to organic materials; it is not effective against biofilms and can chemically combine with some organics to form toxic compounds such as trichloromethane and other derivatives of natural hydrocarbons. Also, the $\mathrm{pH}$ of chlorine used for sanitation applications must be carefully regulated for optimum efficacy, limiting the practical use of chlorine.

In our laboratory, we have tested alternative methods of sanitation and have found that commercial solutions of peroxyacetic acid (PAA) sanitize fruit surfaces more efficiently and consistently than chlorine. For these studies we compared washing fruit surfaces with warm tap water, sodium hypochlorite $(\mathrm{NaOCl}, 200$ ppm, pH 6.5) and PAA (100 ppm). Initially a sampling of the populations of microorganisms found on orange surfaces was enumerated (Fig. 2). Data show that microflora of fruit and vegetable surfaces change with season and other environmental parameters. These changing populations vary the amount of organic material on the fruit surface and should be taken into account when choosing a sanitizer.

For our study, experimental orange fruits were collected in the spring and fall, cleaned of any residual microorganisms and inoculated with a suspension of spores and cells of common citrus pathogens at approximately a $10^{5}$ spores $\cdot \mathrm{mL}^{-1}$. After the inoculum had dried on the fruit surfaces, the organisms were removed with warm water, $\mathrm{NaOCl}$, or PAA by submerging the fruits in the sanitizing solutions and manually agitating them. Trials in both the spring and the fall resulted in data that showed PAA was the most efficient and consistent sanitizer (Fig. 3). PAA readily decomposes into acetic acid and hydrogen peroxide, and is a good candidate as an alternative sanitizer. It was recommended by the NOSB for inclusion on the NOPNational List since November 2000. It was recently (September 16,2005) proposed on the National List for use as a sanitizer for food contact surfaces, but restricted to use directly on agricultural products that will be labeled "made with organic (specified ingredients or food group(s))" (Federal Register, 2005b). The final wording with any possible restrictions will be published in 2006. PAA would be a useful addition to the NOPNational List, as its sanitizing activity has proven consistently superior to chlorine (Narciso and Plotto, 2005).

\section{INGREDIENTS USED TO ENHANCE FRUIT AND FRUIT PRODUCTS QUALITY IN STORAGE}

Another area where research is needed is the development of ingredients compatible with organic practices for lightly processed fruit, and fruit coatings. For example, sulfur compounds such as $\mathrm{SO}_{2}$ cannot be used to prevent browning of organic cut or dried fruit, whereas citric acid or ascorbic acid may be used, but are not as effective. Other natural antioxidants that prevent tissue browning and maintain sensory quality should be investigated for processed fruit. For example, the natural sulfur compounds cysteine or $\mathrm{N}$-acetylcysteine reduced browning of cut fruit (Soliva-Fortuny and Martín-Belloso, 2003) and could be petitioned for approval on the National List. Fruit waxes used to prevent dehydration of citrus and apples in storage, need reformulation to exclude morpholine, currently used in many coatings (Hagenmaier, 2004). Morpholine together with a fatty acid such as linoleic or oleic acids are used to make microemulsions of waxes to allow their application on fruit. Ammonia does not remain in the coating due to its high volatility (Hagenmaier and Baker, 1997), and therefore offers a possible alternative to morpholine. Hagenmaier, (2004), and Hagenmaier and Baker (1997), have studied the physical properties and effect on citrus gas exchange of experimental coatings made with ammonia instead of morpholine.

\section{TEMPORARY VARIANCES}

The NOP provides temporary exemption to adherence to standards for research purposes (\$205.290). This however does not include the use of ionizing irradiation, sewage sludge, and materials derived from genetic engineering, or any prohibited substances. Growers and researchers working collaboratively to enhance organic production methods should be aware of the temporary and exceptional nature of the variance to the rule.

\section{CONCLUSION}

With the periodic reevaluation of the National List, the industry, growers, packers and processors, need to continue to develop techniques not relying on synthetics. As of this writing, chlorine-based sanitizers, hydrogen peroxide and ozone can be used for sanitation. However, these synthetic substances may not be available in the future. Considering the size of the market and the value added to organic crops (many growers would have lost their business had they not converted to organic farming), the risk of not using proper sanitation is too high. Small growers cannot afford to lose a crop to postharvest diseases, and the whole industry cannot afford a tarnished reputation due to food-borne illnesses caused by ingesting improperly sanitized organic foods. Research is needed to help the industry provide consumers with safe high quality food by developing techniques adapted to the regulations.

\section{Websites}

International Federation of Organic Movement (IFOAM): http://www.ifoam.org

National Organic Standard Board: http://www.ams usda.gov/NOSB/index.htm

Organic Farming Research Foundation: http://www. ofrf.org/

Organic Materials Review Institute: http://www. omri.org

Organic Research database: http://www.organicresearch.com/

Organic Trade Association: http://www.ota.com/

USDA Economic Research Service: www.ers.usda. gov/briefing/Organic/ 
United States National Organic Program: http:// www.ams.usda.gov/nop/

\section{Literature Cited}

Baldwin, E.A. 1994. Edible coatings for fresh fruits and vegetables: Past, present, and future, p. 25-64. In: J.M. Krotcha, E.A. Baldwin, and M. Nisperos-Carriedo (eds.). Edible coatings and films to improve food quality. Technomic Publ. Co., Lancaster, Pa.

Benbrook, C. 2004. Minimizing pesticide dietary exposure through consumption of organic food. An Organic Center State of Science Review. http://www.organic.center.org/PESTICIDE_SSR.pdf.

Federal Re-gister. 2005a. Docket Number TM-04-07. National Organic Program, Sunset Review. vol. 70. No 116, Friday 17 June. p. 35177-35182.

Federal Register. 2005b. Docket Number TM04-01. National Organic Program, Proposed Amendments to the National List of Allowed and Prohibited Substances (Crops and Processing). vol. 70. No 179. Friday 16 Sept. p. 54665 and 54668 .

Hagenmaier, R.D. 2004. Fruit coatings containing ammonia instead of morpholine. Proc. Fla. State Hort. Soc. 117:396-402.

Hagenmaier, R.D. and R.A. Baker. 1997. Edible coatings from morpholine-free wax microemulsions. J. Agr. Food Chem. 45:349-352.

Montecalvo, J. 2004. Organic pest management operations and requirements. Organic Processing (Oct.-Dec.)2(1):26-29, 56.

Montecalvo, J. 2005. What to expect when you're inspected. Organic Processing (Jan.Mar.)2(2):25-29.

Narciso, J.A. and A. Plotto. 2005. A comparison of sanitation systems for fresh-cut mango. HortTechnology 15:1-6.

Organic Trade Association. 2004. Manufacturer survey overview. http://www.ota.com/pics/ documents/2004SurveyOverview.pdf.

Sahota, A. 2004. Overview of the global market for organic food and drink. In: H. Willer and M. Yussefi (eds.). The world of organic agriculture. Statistics and emerging trends. www.soel.de/inhalte/publikationen/s/s_74.pdf.

Soliva-Fortuny, R.C., and Ō. Martín-Belloso. 2003. New advances in extending the shelf life of fresh-cut fruits: A review. Trends in Food Sci. Technol. 14:341-353.

UNCTAD. 2003. Organic Fruit and Vegetables from the Tropics. Market, certification and production information for producers and international trading companies. A publication of the United Nations Conference on Trade \& Development, New York and Geneva, 2003. http://www.unctad. org/en/docs//ditccom20032_en.pdf.

Youssefi, M. 2005. Current status of organic farming worldwide. In: Willer H., and Yussefi M. (eds.). The world of organic agriculture. statistics and emerging trends. http://www.ifoam.org/press/ press/Statistics-2005.html. 